\title{
Downregulation of BDNF mRNA in the Hippocampal Dentate Gyrus after Re-exposure to Cues Previously Associated with Footshock
}

\author{
Ann M. Rasmusson, M.D., Libin Shi, M.D., and Ronald Duman, Ph.D.
}

This study examined the effects of footshock stress and reexposure to cues previously associated with footshock on expression of brain-derived neurotrophic factor (BDNF) $m R N A$ in the hippocampus of male rats. Exposure to twenty 0.5-s 0.4-mA footshocks co-terminating with $70 \mathrm{~dB}$, 5 -s long pure tones over 60 min decreased dentate gyrus BDNF mRNA by $21.5 \%$. Baseline BDNF mRNA levels returned to normal by two days after footshock exposure. Re-exposure for $60 \mathrm{~min}$ to the chamber and tones previously paired with $0.4 \mathrm{~mA}$ footshock decreased BDNF $\mathrm{mRNA}$ by $12 \%$. Re-exposure to the conditioning chamber and tones previously paired with $0.6 \mathrm{~mA}$ footshock over $60 \mathrm{~min}$ decreased BDNF mRNA by $20.8 \%$. The data suggest that psychological, as well as unconditioned physical stress, can decrease hippocampal BDNF $m R N A$. Possible implications for stress-related and other neuropsychiatric disorders associated with deficits in hippocampal function and volume, such as depression, post-traumatic stress disorder, and Alzheimer's Disease, are discussed.

[Neuropsychopharmacology 27:133-142, 2002] (C) 2002 American College of Neuropsychopharmacology. Published by Elsevier Science Inc.
KEY WORDS: BDNF mRNA; Hippocampus; Dentate gyrus; Footshock stress; Psychological stress; Male rats

Brain-derived neurotrophic factor (BDNF) is a member of the neurotrophin family of growth factors, which also

From the VA National Center for PTSD, Clinical Neuroscience Division, West Haven, CT (AMR, RD), Department of Psychiatry (AMR, LS, RD), and Department of Pharmacology (RD), Yale University School of Medicine, New Haven, CT.

Address correspondence to: Ann M. Rasmusson, M.D., Psychiatry Service/116A VA Connecticut Healthcare System, 950 Campbell Ave., West Haven, CT 06516, Tel.: (203) 932-5711 ext. 2483 or 2464; Fax: (203) 937-3886; Page: (203) 867-3132; E-mail: ann.rasmusson @yale.edu

Received August 20, 2001; revised December 17, 2001; accepted January 8, 2002.

Online publication: 1/14/02 at www.acnp.org/citations/ Npp011402224.

Previous Presentations: Presentation for the 13th Annual Meeting for The International Society for Traumatic Stress Studies, November 6-10, 1997; Society for Neuroscience Abstracts, 23, 1997. includes nerve growth factor and neurotrophins 3 and 4. BDNF as well as these other neurotrophins, plays an important role in neuronal growth and differentiation during development, and also contributes to the survival, function, and plasticity of neurons in the adult brain (Lewin and Barde 1996). Thus, through a variety of mechanisms in different brain regions, BDNF has been implicated in emergent phenomena such as learning and memory (Patterson et al. 1996; Mu et al. 1999) and even contributes to the modulation of overt behaviors such as aggression (Lyons et al. 1999). The ability of BDNF to influence these processes is related, in part, to the activity dependent regulation of BDNF expression in adult brain (Lewin and Barde 1996).

BDNF is also thought to play a role in the cellular and behavioral responses to stress (Duman et al. 1997, 2000). Exposure to physical stress, such as immobilization, downregulates BDNF expression in the hippocampus (Smith et al. 1995, Vaidya et al. 1997, 1999). Decreased 
expression of BDNF is hypothesized to play a role in the atrophy of hippocampal neurons in experimental animals in response to stress (Duman et al. 1997, 2000). Moreover, downregulation of BDNF could contribute to the hippocampal pathology observed in psychiatric disorders such as post-traumatic stress disorder (PTSD) and depression (Bremner et al. 2000; Mervaala et al. 2000; Vakili et al. 2000). This possibility is supported by the observation that these disorders are sensitive to stressful experiences (Breslau et al. 1995; Kendler et al. 2000). Based on these observations and findings, we became interested in determining whether psychological stress has a measurable impact on hippocampal BDNF expression similar to the effects of physical stressors that have been reported.

We therefore tested the effects of psychological stress produced by exposures to cues previously paired with footshock on BDNF mRNA levels in the dentate gyrus of the hippocampus. We hypothesized that re-exposure to cues associated with footshock stress, as well as footshock itself, would decrease BDNF mRNA in the dentate gyrus. The results demonstrate that this type of psychological stress produces a heightened sensitivity to previously neutral cues that results in downregulation of BDNF, and suggest that psychological stress, such as that experienced in association with PTSD and depression, as well as other disorders, could result in decreased neurotrophic support of the hippocampus.

\section{MATERIAL AND METHODS}

\section{Animals}

Adult male Sprague-Dawley rats were kept in a 12:12 h light-dark cycle (lights on at 7:00 A.M.) for 7-10 days before each experiment. The animals were housed two or three per cage and fed ad libitum. Experiments were conducted between 9:00 A.M. and 6:00 P.M. To control for possible effects of diurnal variation on hippocampal BDNF mRNA levels (Berchtold et al. 1999; Schaaf et al. 2000), animals from each experimental condition were treated and sacrificed in an alternating order. To control for possible effects of isolation stress on hippocampal BDNF mRNA levels, animals from each experimental condition were alternately taken first from the home cage. The rats weighed between 300 and 400 grams at the time of sacrifice. Animal care and experimental procedures were conducted in strict accordance with the Yale University Animal Care and Use Committee guidelines.

\section{Conditioning and Testing Apparatus}

Animals were placed in a standard conditioning chamber housed within a sound attenuation chamber during initial fear conditioning and subsequent re-exposure to cues previously paired with footshock. Remote behav- ioral monitoring was achieved by use of an infrared television camera (Sanyo Electronics, Japan) and infrared illuminator positioned over the test cage and connected to a video recording system. Tone-footshock pairings or tones alone were triggered using AcqKnowledge III for the MP100WS hardware and software (BIOPAC Systems, Inc., Goleta, CA).

\section{Behavioral Assessments}

Animal behaviors were coded from video recordings of sessions in which animals were re-exposed to the conditioning chamber using AcqKnowledge III for the MP100WS hardware and software (BIOPAC Systems, Inc., Goleta, CA). Freezing and locomotion were evaluated and scored as previously described (Goldstein et al. 1996). Freezing was coded when there was an absence of visible movement, including movement of vibrissae, except that related to respiration. Crossings were counted each time the base of an animal's tail crossed a gridline on a video monitoring screen divided into nine squares.

\section{Experimental Design}

The experimental paradigms are illustrated in Figure 1. In experiment 1 (Figure 1, top), we tested for the effects of unconditioned footshock stress on dentate gyrus BDNF mRNA levels. Animals were exposed over $60 \mathrm{~min}$ to twenty 5-s $<70 \mathrm{~dB}$ tones, co-terminating with a 0.5-s 0.4-mA footshock (Goldstein et al. 1996). The tone-footshock pairings were provided randomly within each 3 -min interval of the $60-\mathrm{min}$ conditioning session. The animals were sacrificed by decapitation at the end of the conditioning session. Their brains were immediately removed and frozen on dry ice prior to storage at $-70^{\circ}$. The control group was sacrificed upon removal from the home cage without exposure to the conditioning chamber or tone-footshock pairings.

In experiment 2 (Figure 1, middle), we tested for the effects of re-exposure to the context and tones previously paired with $0.4 \mathrm{~mA}$ footshock on dentate gyrus BDNF mRNA levels. (1) A group of rats was exposed to the conditioning procedure described above, returned to the home cage for two days, and re-exposed to the conditioning chamber and twenty 5 -s tones over a 60 -min period prior to sacrifice; (2) a control group was exposed to the conditioning procedure, returned to the home cage for two days, and then sacrificed; and (3) a second control group was exposed to the conditioning chamber and tones alone for the first session, returned to the home cage for two days, and then re-exposed to the conditioning chamber and tones alone for $60 \mathrm{~min}$ prior to sacrifice.

In a third set of experiments (Figure 1, bottom), we tested for the effects of re-exposure to the context and tones previously paired with $0.6 \mathrm{~mA}$ footshock on dentate gyrus BDNF mRNA levels. In the first experiment 


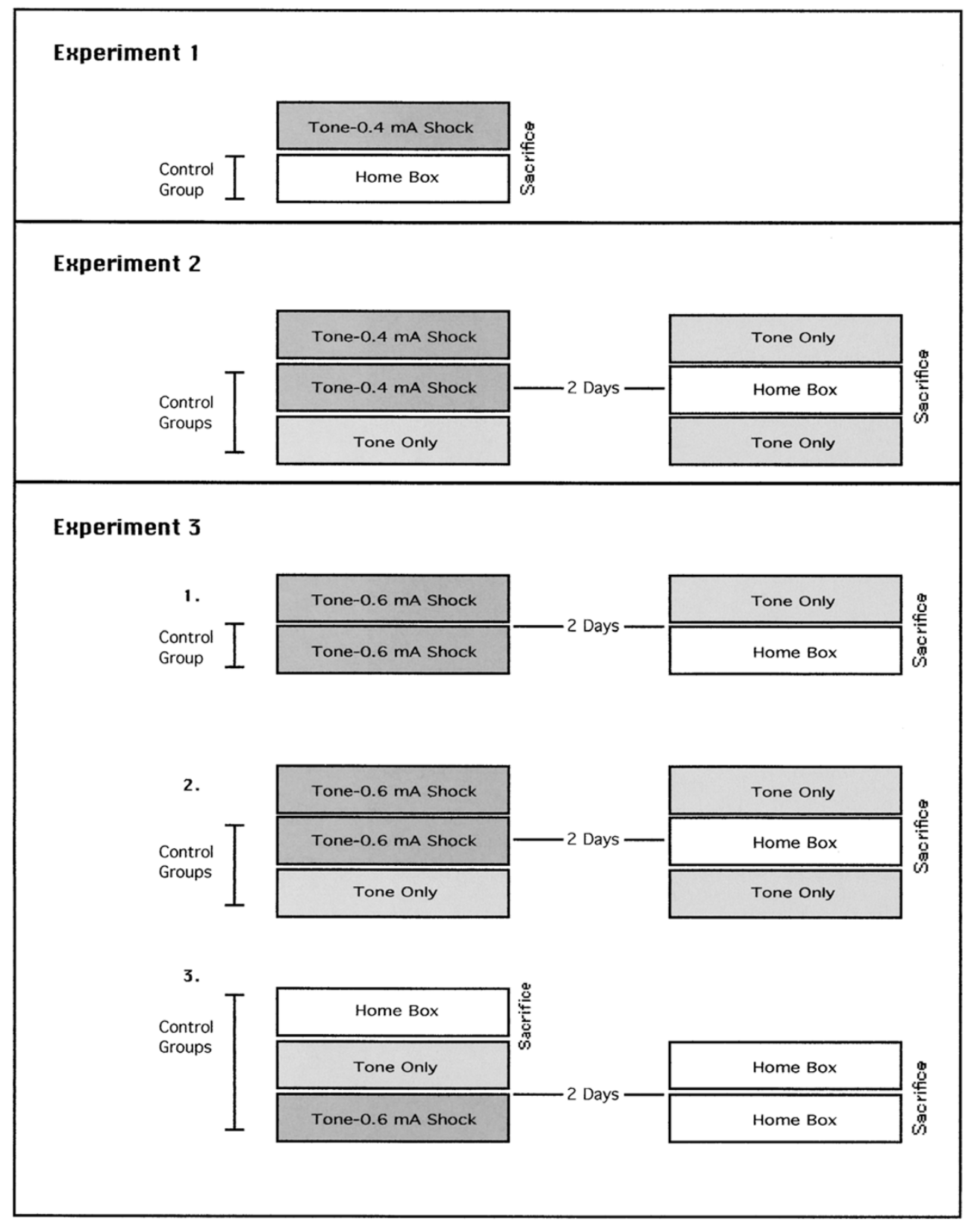

Figure 1. Diagrammatic representations of the experimental paradigms used in the current study. See the text for a precise description of the conditioning methods and other procedures indicated.

of this series, a group of rats was exposed to the conditioning procedure described above, except that footshock was provided at $0.6 \mathrm{~mA}$. The rats were then returned to their home cages for two days before being re-exposed to the conditioning chamber and tones for $60 \mathrm{~min}$ prior to sacrifice. The control group was exposed to the same conditioning procedure and returned to the home cage for two days before sacrifice.

In the second experiment in this series, the above experiment was repeated with a second control group added. Rats were exposed to the conditioning procedure with footshock at $0.6 \mathrm{~mA}$ and then were re-exposed to the con- ditioning chamber and tones over a 60 min session two days later. This group was compared with either (1) a control group exposed to the same conditioning procedure and returned to the home cage for two days before sacrifice; or (2) a control group exposed to the conditioning chamber and tones alone for the first session, returned to the home cage for two days, and re-exposed to the conditioning chamber and tones for $60 \mathrm{~min}$ before sacrifice.

In the third experiment of this series, three control groups were directly compared: (1) one group of rats was sacrificed upon removal from the home cage without exposure to the conditioning chamber or tone-foot- 
shock pairings; (2) a second group of rats was exposed to the conditioning chamber and tone alone for the first session and returned to the home cage for two days before sacrifice; and (3) a third group of rats was exposed to tone and footshock at $0.6 \mathrm{~mA}$ in the conditioning chamber for the first session and returned to the home cage for two days before sacrifice.

\section{BDNF mRNA Measurements}

Immediately after sacrifice, animal brains were sectioned and frozen on dry ice before storage in a $-70^{\circ}$ freezer. In situ hybridization and quantification of BDNF mRNA were performed as previously described (Vaidya et al. 1997).

\section{Statistical Analyses}

Due to significant variation in the intensity of staining among slides, a brain slice from each treatment condition was placed on each slide and the data were analyzed using analysis of variance (ANOVA) with treatment condition and slide number as independent factors. (The one exception to this procedure was the first experiment investigating the effects of re-exposure to cures previously associated with $0.6 \mathrm{~mA}$. In that case, slices from each condition were not placed together on slides; therefore, the data was analyzed using a 1-way ANOVA with condition as the only independent factor.) Student-NewmanKeuls post hoc tests were used, as appropriate, when the ANOVA indicated a significant difference in BDNF mRNA among experimental groups. Due to human error associated with the recording of animal behaviors, behavioral data was available consistently only for the first $30 \mathrm{~min}$ of each testing session. Therefore animal behaviors, including freezing and crossings, were analyzed for the first $30 \mathrm{~min}$ of each testing session using ANOVA. Significance was set at $p<0.05$.

\section{RESULTS}

\section{Behavioral Effects of Re-exposure to the Context and Tones Previously Paired with Footshock}

As indicated in Table 1, rats re-exposed to the conditioning apparatus and tones previously paired with either 0.4 or $0.6 \mathrm{~mA}$ footshock showed significantly greater freezing and less locomotion during the first $30 \mathrm{~min}$ of re-exposure to the chamber compared with animals exposed to the chamber and tones alone during both the first and second sessions.

\section{Effects of Unconditioned Footshock Stress (US) on Dentate Gyrus BDNF mRNA Levels}

Analysis of the data revealed that exposure to the conditioning apparatus and 20 tone-footshock pairings over
60 min decreased dentate gyrus BDNF by $21.5 \%: \mathrm{F}_{1,4}=$ $10.67, p<.04$. See Figure 2.

\section{Effects of Re-exposure to the Context and Tones Previously Paired with $0.4 \mathrm{~mA}$ Footshock}

There was an effect of treatment on dentate gyrus BDNF mRNA levels: $\mathrm{F}_{2,8}=4.82, p<.05$, and Student-Newman-Keuls post hoc testing revealed a significant $12.0 \%$ decrease in dentate gyrus BDNF mRNA in the group exposed to footshock and re-exposed to the context and tones previously paired with footshock compared with the group exposed to footshock and returned home for two days before sacrifice $(p<.05)$. The $9.5 \%$ decrease in BDNF mRNA levels in the group re-exposed to the cues previously paired with footshock compared with the group exposed to the conditioning chamber and tones alone during the first and second sessions was not significant $(p=.14)$. See Figure 3 .

\section{Effects of Re-exposure to the Context and Tones Previously Paired with $0.6 \mathrm{~mA}$ Footshock}

In the first experiment, animals re-exposed to the conditioning apparatus and tones over $60 \mathrm{~min}$ had a $17.2 \%$ decrease in dentate gyrus BDNF mRNA compared with animals not re-exposed to footshock-related cues: $\mathrm{F}_{1,12}=$ $16.22, p<.002$ (not illustrated).

Analysis of data from the second experiment revealed a significant $20.8 \%$ decrease in dentate gyrus BDNF in the group re-exposed to the conditioning chamber and tones previously paired with $0.6 \mathrm{~mA}$ footshock compared with the group that was conditioned but not re-exposed to the chamber and tones: $\mathrm{F}_{1,4}=7.90, p<.05$ (Figure 4, top). There was a significant $12.5 \%$ decrease in dentate gyrus BDNF in the group re-exposed to the conditioning chamber and tones previously paired with $0.6 \mathrm{~mA}$ FS compared with the control group in which animals were exposed to the chamber and tones alone during both the first and second sessions: $\mathrm{F}_{1,5}=6.78, p<.05$ (Figure 4, middle).

In the third experiment, there was no difference in dentate gyrus BDNF levels among the three control groups examined: $\mathrm{F}_{2,12}=0.05, p=.95$ (Figure 4 , bottom).

\section{DISCUSSION}

The current study demonstrates that exposure to unconditioned footshock stress, as well as re-exposure to cues previously paired with footshock, decreases BDNF mRNA in the dentate gyrus of the hippocampus of male rats (Figures 1 and 2). It should be appreciated, however, that the current study does not demonstrate "conditioning" of dentate gyrus BDNF mRNA decreases, per se. Animals exposed to extreme stress may simply become 
Table 1. Freezing and Locomotion during the First 30 Minutes of Re-Exposure to the Conditioning Chamber and Tones in Fear-Conditioned Rats and Controls

\begin{tabular}{lcc}
\hline Previous Stress Exposure & Freezing (minutes) & Crossings (\#) \\
\hline Tone/0.4 mA Footshock Pairings $(\mathrm{n}=4)$ & $* * * * 24.8 \pm 3.2$ & $* 6.0 \pm 3.1$ \\
Tones Alone $(\mathrm{n}=5)$ & $1.1 \pm 0.4$ & $60.6 \pm 17.2$ \\
Tone/0.6 mA Footshock Pairings $(\mathrm{n}=6)$ & $* * 23.9 \pm 4.8$ & $* .2 \pm 0.0 \pm 1.3$ \\
Tones Alone $(\mathrm{n}=4)$ & $0.3 \pm 0.2$ & $77.2 \pm 16.4$ \\
\hline${ }^{*} p<.05, * * p<.01, * * * p<.001, * * * * p .0001$ indicate significant differences in freezing or crossing between \\
groups previously exposed to tone/footshock pairing and tone alone in the conditioning chamber. Behaviors \\
were not recorded due to human error for one rat in the tone-0.4mA footshock pre-exposed group and for \\
two rats in the group exposed to tone alone in the first session and compared to rats in the 0.6mA tone-foot- \\
shock pre-exposed group.
\end{tabular}

more sensitive to provocations of any sort, including novelty (Aguilera 1998). Thus further controlled experiments must be done to establish whether the observed decreases in dentate gyrus BDNF mRNA in response to psychological stress result from, and only from, a learned association between the experience of footshock and formerly neutral sensory cues.

The stress-induced decreases in dentate gyrus BDNF mRNA in this study were less than those seen in studies where animals were exposed to $2 \mathrm{~h}$ of immobilization stress (Smith et al. 1995, Vaidya et al. 1997, 1999). This suggests that the intensity, duration, and/or type of stress exposure may influence the degree to which dentate gyrus BDNF mRNA decreases. For instance, the magnitude or duration of stress-associated increases in hippocampal corticosterone exposure (Smith et al. 1995), activation of serotonergic $5-\mathrm{HT}_{2 \mathrm{~A}}$ receptors (Vaidya et al. 1997, 1999; Zetterstrom et al. 1999), or enhancement of GABAergic transmission (Berninger et al. 1995) may influence the magnitude of dentate gyrus BDNF mRNA decreases.

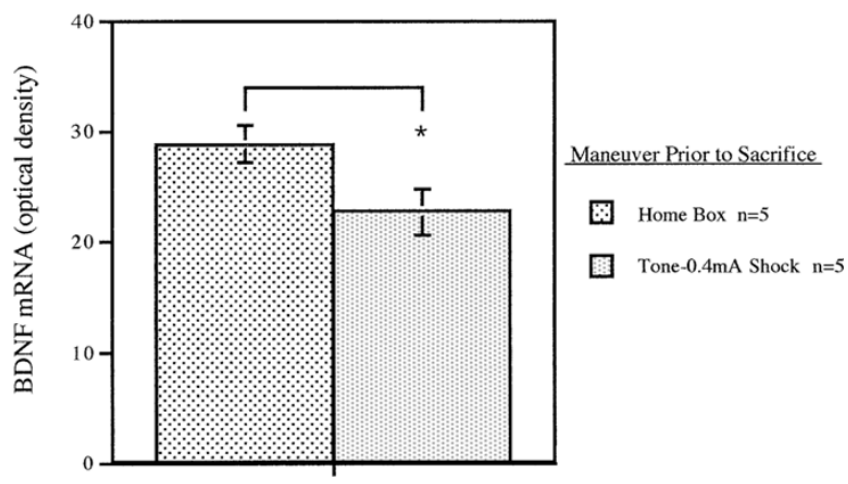

Figure 2. Effects of unconditioned $0.4 \mathrm{~mA}$ footshock stress on hippocampal dentate gyrus BDNF mRNA. Rats were exposed to twenty 5-s $<70 \mathrm{~dB}$ tones, co-terminating with a 0.5 -s $0.4-\mathrm{mA}$ footshock provided randomly within each 3-min interval of a 60 -min conditioning session. The control group was sacrificed upon removal from the home cage. ${ }^{*} p<$ .05 compared with control group (ANOVA).
From the current study, it is also apparent that decreases in dentate gyrus BDNF mRNA levels after 60 min of exposure to footshock stress are transient since BDNF mRNA levels were restored to normal within $48 \mathrm{~h}$. This may be consistent with work by Kuroda and McEwen (1998) showing dentate gyrus BDNF mRNA levels $21 \mathrm{~h}$ after 21 consecutive days of $6 \mathrm{~h}$ restraint stress sessions to be no different from unstressed controls. Thus the precise length of time over which BDNF mRNA levels remain decreased after acute physical or psychological stress (Smith et al. 1995, Vaidya et al. 1997, the current study) or after chronic episodic stress (Kuroda and McEwen 1998) needs to be more closely examined. In addition, it will be important to know whether repeated exposure to a single or to varied unconditioned or psychological stressors results in repeated transient decreases in hippocampal BDNF mRNA or whether these effects are subject to habituation or extinction. Finally, it must be determined whether the decreases in dentate gyrus BDNF mRNA levels observed in the current study are associated with decreases in the expression of BDNF protein. If so, it is conceivable that even episodic withdrawal of neurotrophin support could result in a remodeling of hippocampal structure that is sustained.

Consistent with previous studies using similar fearconditioning procedures (Goldstein et al. 1996; Morrow et al. 1999), rats exposed to cues previously associated with $0.4 \mathrm{~mA}$ or $0.6 \mathrm{~mA}$ footshock engaged in freezing behaviors for most of the 60-min tone and context re-exposure session. It seems unlikely, however, that decreases in physical activity account for the observed decreases in dentate gyrus BDNF mRNA in rats exposed to unconditioned footshock stress or cues previously paired with footshock. Work by others shows that dentate gyrus BDNF mRNA levels increase after two days (Neeper et al. 1996), but not $6 \mathrm{~h}$ of wheel running (Oliff et al. 1998). In the current work, rats exposed to the conditioning chamber and tones alone during the first session showed only mild degrees of locomotion when re-exposed to the conditioning chamber. In addition, analysis of crossing behaviors over time revealed a progressive and signifi- 


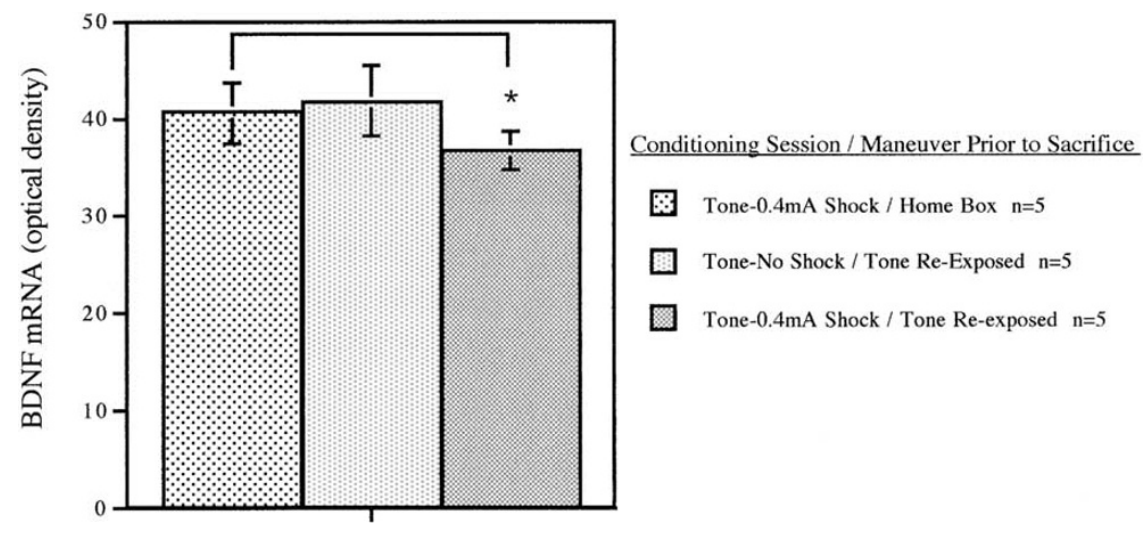

Figure 3. Effects of re-exposure to cues previously paired with $0.4 \mathrm{~mA}$ footshock stress on hippocampal dentate gyrus BDNF mRNA. Stressed rats were re-exposed for $60 \mathrm{~min}$ to the conditioning chamber and tones previously paired with intermittent 0.4-mA footshock. The first control group was sacrificed upon removal from the home cage two days after exposure to intermittent 0.4-mA footshock. The second control group was exposed to the conditioning chamber and tones without footshock for both sessions. ${ }^{*} p<.05$ compared with the first control group (ANOVA).

cant decline in crossings to a stable low level by $30 \mathrm{~min}$ into the 60-min re-exposure period (data not shown). On the other hand, Oliff et al. (1998) also showed that 6 h of wheel running selectively increased some of the specific transcripts of the BDNF gene, even though the level of full-length BDNF mRNA encoding the mature BDNF protein was not increased. Thus, it would be interesting to see whether levels of specific transcripts of the BDNF gene are differentially changed by unconditioned or conditioned stress exposure.

As noted previously, BDNF is a member of the neurotrophin family of peptides and has been shown to support neuronal growth, differentiation, and survival in the developing and adult hippocampus (Lewin and Barde 1996). In addition, reduction in the expression of endogenous BDNF has been shown to potentiate seizures induced by hippocampal kindling (Reibel et al. 2000). The current work thus raises the possibility that reductions in hippocampal BDNF mRNA induced by uncondititioned stress or by re-exposure to cues previously paired with stress may be involved in the pathophysiology of hippocampus-dependent memory disturbances or decreases in hippocampal volume observed in stress-sensitive psychiatric disorders such as PTSD (Bremner et al. 1995; Stein et al. 1997; Gurvits et al. 1996; Bremner et al. 1997) and depression (Mervaala et al. 2000; Vakili et al. 2000). This also raises the possibility that unconditioned or psychological stress may facilitate the progression of dementing disorders such as Alzheimer's disease in which decreases in hippocampal BDNF levels (Hock et al. 2000) and hippocampal volume (Laakso et al. 2000) have been found. Alternatively, it is possible that stressinduced decreases in hippocampal BDNF levels may underly disturbances in memory and cognition common to several disorders that may otherwise vary in their etiology and symptom profiles (Wolfe and Schlesinger 1997; Yousef et al. 1998).
Also of possible pertinence to such clinical neuropsychiatric disorders, BDNF has been shown to be essential to long-term potentiation (LTP), a cellular process proposed to underly learning and memory (Patterson et al. 1996). Consistent with a role for BDNF in learning, rats pre-treated with anti-BDNF antibodies show impairments in spatial learning and memory ( $\mathrm{Mu}$ et al. 1999). Conversely, animals that learn the location of a platform in a water maze show increased hippocampal BDNF mRNA levels compared with activity-yoked controls (Kesslak et al. 1998).

Recent work also has assigned a more explicit role for the dorsal hippocampus, which includes the dentate gyrus, in mediating behaviors associated with spatial learning, fear conditioning, and appetitive instrumental conditioning. For instance, selective colchicine lesions of the dentate gyrus produce deficits in tasks requiring spatial working and reference memory (Xavier et al. 1999). Electrolytic lesions of the dorsal hippocampus induce anterograde deficits in contextual fear conditioning (Maren and Fanselow 1997). Transient pharmacologic inactivation of the dorsal hippocampus by muscimol infusion interferes with the contextual specificity of latent inhibition (Holt and Maren 1999). And finally, animals with electrolytic lesions of the dorsal hippocampus seem to be unable to modify their behavior when inaction becomes equally as likely as a previously learned instrumental action to result in food delivery (Corbit and Balleine 2000). The authors (Corbit and Balleine 2000) suggest that animals with dorsal hippocampus lesions are unable to calculate competing rates of reinforcement based on context-outcome associations and thus continue to attribute the desired outcome to a specific action.

Thus, we believe it is interesting, as well as reasonable, to speculate about the impact of stress-induced decreases in dentate gyrus BDNF mRNA on learning under conditions of stress. For example, a decrease in the 

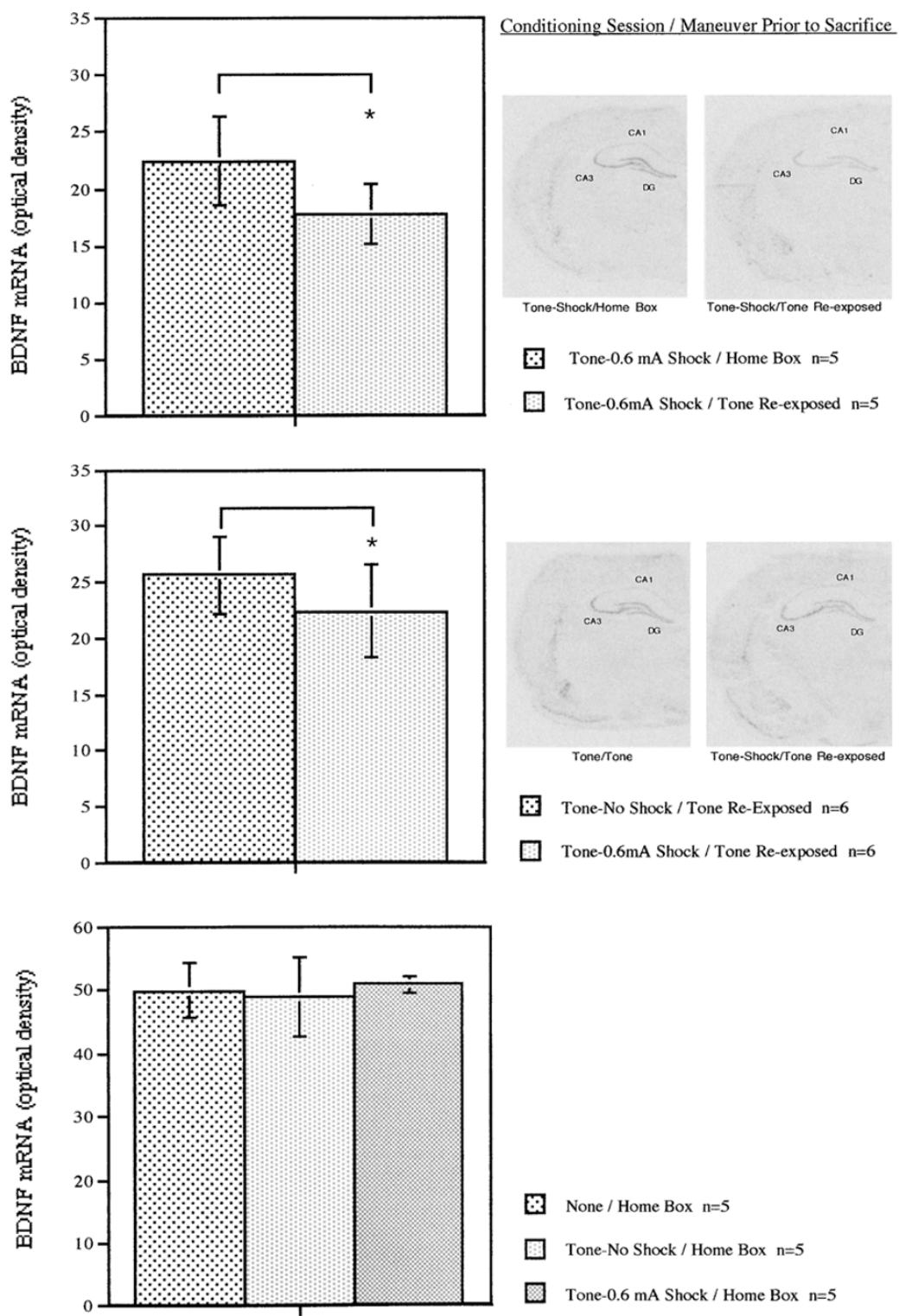

None / Home Box $\mathrm{n}=5$
Tone-No Shock / Home Box $\mathrm{n}=5$
Tone- $0.6 \mathrm{~mA}$ Shock / Home Box $\mathrm{n}=5$

Figure 4. Effects of re-exposure to cues previously paired with $0.6 \mathrm{~mA}$ footshock stress on hippocampal dentate gyrus BDNF mRNA. Top: Stressed rats were re-exposed for $60 \mathrm{~min}$ to the conditioning chamber and tones previously paired with intermittent $0.6-\mathrm{mA}$ footshock. The control group was sacrificed upon removal from the home cage two days after exposure to intermittent $0.6 \mathrm{~mA}$ footshock. Middle: Stressed rats were re-exposed for $60 \mathrm{~min}$ to the conditioning chamber and tones previously paired with intermittent $0.6 \mathrm{~mA}$ footshock. The control group was exposed to the conditioning chamber and tones without footshock during both sessions. Bottom: Comparison of the effects of three control conditions on dentate gyrus BDNF mRNA. The first group was sacrificed after removal from the home cage. The second group was exposed to the conditioning chamber and tone alone for the first session and returned to the home cage for two days before sacrifice. The third group was sacrificed upon removal from the home cage two days after exposure to 20 tone and $0.6 \mathrm{~mA}$ footshock pairings over 60 min. There were no differences in dentate gyrus BDNF mRNA levels among these groups. ${ }^{*} p<.05$ compared with control group (ANOVA).

capacity for dentate gyrus BDNF expression during stress may result in a reduction in the capacity of the hippocampus to encode adventitious contextual stimuli that would otherwise compete with phasic stimuli associated more closely and consistently with an unconditioned stressor. A stress-induced reduction in hippocampal BDNF also may limit the extent to which previously learned associations can be linked with or "brought to bear" on new threatening experiences. These possibilities are supported by the observation that recent exposure to stress facilitates classical conditioning in male rats (Shors et al. 1992); indeed, this stress-related facilitation "overrides" the suppressive effect on classical conditioning of previous inhibitory conditioning, an effect that normally relies 
on the hippocampus (Beylin and Shors1998). In addition, the facilitation of classical conditioning by recent stress in male rats has been found to be unaltered by hippocampus lesions, a phenomenon that could be explained if hippocampal influence is normally compromised under such circumstances. And finally, the facilitation of classical conditioning by recent stress can be re-instated by re-exposing the rat to the previously stressful context alone (Shors and Servatius 1997), a situation in which the current study would predict that dentate gyrus BDNF mRNA would be decreased.

Thus, we propose that stress-induced decreases in dentate gyrus BDNF mRNA may shift the type of learning that prevails under stress in a manner that may be expected to enhance immediate survival. However, such a phenomenon also may be relevant to human psychopathology as suggested by studies of patients with PTSD. In PTSD, facilitation of classical conditioning (Grillon and Morgan 1999; Orr et al. 2000) and deficits in hippocampal volume and hippocampus-dependent tasks such as declarative memory (Bremner et al. 1995; Stein et al. 1997; Gurvits et al. 1996; Bremner et al. 1997) appear to co-occur, at least in males.

The current work also suggests a potential mechanism by which re-exposure to trauma-related cues might disrupt the formation of more complex associations, such as those required by extinction, and thus undermine the efficacy of exposure therapy in some individuals with PTSD (Jaycox et al. 1998). It is also intriguing to consider the possibility that acute stress-induced decreases in hippocampal BDNF mRNA may prevent the initial encoding of contextual material associated with a traumatic experience. This could underlie the partial or total amnesia (i.e. failure of conscious recall) for the experience manifested by some individuals that develop PTSD or dissociative identity disorders after trauma (Ellason et al. 1996; Lewis et al. 1997). This also may explain why some individuals with PTSD fail to exhibit conditioned avoidance or strategic planning when confronted with situations or contexts that should be regarded as potentially dangerous, deleterious, or on balance, non-rewarding.

As has been previously suggested, rectification of hippocampal BDNF levels may be one process by which the chronic administration of antidepressants could exert their therapeutic effects in disorders such as depression and PTSD (Duman et al. 1997, 2000; Hidalgo and Davidson 2000; Chen et al. 2001). Whether or not antidepressants or other agents that increase hippocampal BDNF could protect against the development of PTSD or depression, enhance the efficacy of cognitive therapies for these disorders, or even forestall the progression of Alzheimer's disease or other dementing disorders has yet to be established. In the meantime, further work must be done to clarify the role of stress-associated reductions in hippocampal BDNF mRNA, as well as $\mathrm{BDNF}$, in learning and memory. In addition, given re- cently described sex differences in the effects of stress on learning (Shors 1998), as well as sex-related differences in the incidence and prevalence of mood and anxiety disorders such as PTSD (Breslau et al. 1997) and major depression (Kendler et al. 2001), future investigations into possible sex differences in the molecular biology of hippocampal BDNF expression need to be undertaken. And finally, it may be fruitful to further investigate a role for functional BDNF gene polymorphisms on learning and memory (Egan et al. 2001), as well as on the risk for development of neuropsychiatric disorders associated with hippocampal pathology or dysfunction.

\section{ACKNOWLEDGMENTS}

This work was supported by the Veterans Administration National Center for Posttraumatic Stress Disorder, Clinical Neuroscience Division, the National Alliance for Research in Schizophrenia and Depression (NARSAD) Young Investigator Award to Dr. Rasmusson, and USPHS grants MH45481, MH53199, and 2P01MH25642 to Dr. Duman.

\section{REFERENCES}

Aguilera G (1998): Corticotropin releasing hormone, receptor regulation and the stress response. Trends Endocrinol Metab 9:329-336

Berchtold NC, Oliff HS, Isackson P, Cotman CW (1999): Hippocampal BDNF mRNA shows a diurnal regulation, primarily in the exon III transcript. Mol Br Res 71:11-22

Berninger B, Marty S, Zafra F, da Penha Berzaghi M, Thoenen $H$, Lindholm D (1995): GABAergic stimulation switches from enhancing to repressing BDNF expression in rat hippocampal neurons during maturation in vitro. Development 121:2327-2335

Beylin AV, Shors TJ (1998): Stress enhances excitatory trace eyeblink conditioning and opposes acquisition of inhibitory conditioning. Behav Neurosci 112:1327-1338

Bremner J, Randall P, Scott T, Bronen R, Seibyl J, Southwick S, Delaney R, McCarthy G, Charney D, Innis R (1995): MRI-based measurement of hippocampal volume in combat-related posttraumatic stress disorder. Am J Psychiatry 152:973-981

Bremner JD, Randall P, Vermetten E, Staib L, Bronen RA, Mazure C, Capelli S, McCarthy G, Innis RB, Charney DS (1997): Magnetic resonance imaging-based measurement of hippocampal volume in posttraumatic stress disorder related to childhood physical and sexual abuse-a preliminary report. Biol Psychiatry 41:23-32

Bremner JD, Narayan M, Anderson ER, Staib LH, Miller HL, Charney DS (2000): Hippocampal volume reduction in major depression. Am J Psychiatry 157:115-118

Breslau N, Davis GC, Andreski P (1995): Risk factors for PTSD-related traumatic events: a prospective analysis. Am J Psychiatry 1152:529-535

Breslau N, Davis GC, Andreski P, Peterson EL, Schultz LR 
(1997): Sex differences in posttraumatic stress disorder. Arch Gen Psychiatry 54:1044-1048

Chen B, Dowlatshahi D, MacQueen GM, Wang J-F, Young LT (2001): Increased hippocampal BDNF immunoreactivity in subjects treated with antidepressant medication. Biol Psychiatry 50:260-265

Corbit LH, Balleine BW (2000): The role of the hippocampus in instrumental conditioning. J Neurosci 20:4233-4239

Duman RS, Heninger GR, Nestler EJ (1997): A molecular and cellular theory of depression. Arch Gen Psychiatry 54:597-606

Duman RS, Malberg J, Nakagawa S, D'Sa C (2000): Neuronal plasticity and survival in mood disorders. Biol Psychiatry 48:713-714

Egan MF, Goldberg TE, Kolachana BS, Callicott JH, Goldman D, Weinberger DR (2001): Effects of BDNF Met66Val genotype on verbal memory and risk for schizophrenia. Soc Neurosci Abstr Vol. 27, Program No. 110.23

Ellason JW, Ross CA, Fuchs DL (1996): Lifetime axis I and II comorbidity and childhood trauma history in dissociative identity disorder. Psychiatry 59:255-266

Hock C, Heese K, Hulette C, Rosenberg C, Otten U (2000): Region-specific neurotrophin imbalances in Alzheimer disease: decreased levels of brain-derived neurotrophic factor and increased levels of nerve growth factor in hippocampus and cortical areas. Arch Neurol 57:846-851

Goldstein LE, Rasmusson AM, Bunney BS, Roth RH (1996): Role of the amygdala in the coordination of behavioral, neuroendocrine and prefrontal cortical monoamine responses to psychological stress in the rat. J Neurosci 16:4787-4798

Grillon C, Morgan CA III (1999): Fear-potentiated startle conditioning to explicit and contextual cues in Gulf War veterans with posttraumatic stress disorder. J Abnorm Psychol 108:134-142

Gurvits T, Shenton M, Hokama H, Ohta H, Lasko N, Gilbertson M, Orr S, Kikinis R, Jolesz F, McCarley R, Pitman R (1996): Magnetic resonance imaging study of hippocampal volume in chronic, combat-related posttraumatic stress disorder. Biol Psychiatry 40:1091-1099

Hidalgo RB, Davidson JR (2000): Selective serotonin reuptake inhibitors in post-traumatic stress disorder. J Psychopharm 14:70-76

Holt W, Maren S (1999): Muscimol inactivation of the dorsal hippocampus impairs contextual retrieval of fear memory. J Neurosci 19:9054-9062

Jaycox LH, Foa EB, Morral A (1998): Influence of emotional engagement and habituation on exposure therapy for PTSD. Ann NY Acad Sci 66:185-192

Kendler KS, Thornton LM, Gardner CO (2000): Stressful life events and previous episodes in the etiology of major depression in women: an evaluation of the "kindling" hypothesis. Am J Psychiatry 157:1243-1251

Kendler KS, Thornton LM, Prescott CA (2001): Gender differences in the rates of exposure to stressful life events and sensitivity to their depressogenic effects. Am J Psychiatry 158:587-593

Kesslak JP, So V, Choi J, Cotman CW, Gomez-Pinilla (1998): Learning up-regulates brain-derived neurotrophic factor messenger ribonucleic acid: a mechanism to facili- tate encoding and circuit maintenance? Behav Neurosci 112:1012-1019

Kuroda Y, McEwen BS (1998): Effect of chronic restraint stress and tianeptine on growth factors, growth-associated protein- 43 and microtubule-associated protein 2 mRNA expression in the rat hippocampus. Mol Br Res 59:35-39

Laakso MP, Frisoni GB, Kononen M, Mikkonen M, Beltramello A, Geroldi C, Bianchetti A, Trabucchi M, Soininen H, Aronen HJ (2000): Hippocampus and entrohinal cortex in frontotemporal dementia and Alzheimer's disease: a morphometric MRI study. Biol Psychiatry 47: 1056-1063

Lewin GR, Barde Y-A (1996): Physiology of the neurotrophins. Annu Rev Neurosci 19:289-317

Lewis DO, Yeager CA, Swica Y, Pincus JH, Lewis M (1997): Objective documentation of child abuse and dissociation in 12 murderers with dissociative identity disorder. Am J Psychiatry 154:1703-1710

Lyons WE, Mamounas LA, Ricaurte GA, Coppola V, Reid SW, Bora SH, Wihler C, Koliatsos V, Tessarollo L (1999): Brain-derived neurotrophic factor-deficient mice develop aggressiveness and hyperphagia in conjuntion with brain serotonergic abnormalities. Proc Natl Acad Sci USA 96:15238-15244

Maren S, Fanselow MS (1997): Electrolytic lesions of the fimbria/fornix, dorsal hippocampus, or entorhinal cortex produce anterograde deficits in contextual fear conditioning in rats. Neurobiol Learn Mem 67:142-149

Mervaala E, Fohr J, Kononen M, Valkonen-Korhonen M, Vainio P, Partanen K, Partanen J, Tiihonen J, Viinamaki H, Karjalainen A-K, Lehtonen J (2000): Quantitative MRI of the hippocampus and amygdala in severe depression. Psychological Med 30:117-125

Morrow BA, Elsworth JD, Rasmusson AM, Roth RH (1999): The role of mesoprefrontal dopamine neurons in the acquisition and expression of conditioned fear in the rat. Neuroscience 92:553-564

Mu J-S, Li W-P, Yao Z-B, Zhou X-F (1999): Deprivation of endogenous brain-derived neurotrophic factor results in impairment of spatial learning and memory in adult rats. Brain Res 835:259-265

Neeper SA, Gomez-Pinilla F, Choi J, Cotman CW (1996): Physical activity increases mRNA for brain-derived neurotrophic factor and nerve growth factor in rat brain Brain Res 726:49-56

Oliff HS, Berchtold NC, Isackson P, Cotman CW (1998): Exercise-induced regulation of brain-derived neurotrophic factor (BDNF) transcripts in the rat hippocampus. Mol Brain Res 61:147-153

Orr SP, Metzger LJ, Lasko NB, Macklin ML, Peri T, Pitman RK (2000): De novo conditioning in trauma-exposed individuals with and without posttraumatic stress disorder. J Abnorm Psychol 109:290-298

Patterson SL, Abel T, Deue TAS, Martin KC, Rose JC, Kandel ER (1996): Recombinant BDNF rescues deficits in basal synaptic transmission and hippocampal LTP in BDNF knockout mice. Neuron 16:1137-1145

Reibel S, Larmet Y, Carnahan J, Marescaux C, Depaulis A (2000): Endogenous control of hippocampal epileptogenesis: a molecular cascade involving brain-derived neurotropic factor and neuropeptide Y. Epilepsia 41:S127S133 
Schaaf MJM, Duurland R, de Kloet R, Vreugdenhil E (2000): Circadian variation in BDNF mRNA expression in the rat hippocampus. Mol Brain Res 75:342-344

Shors TJ (1998): Stress and sex effects on associative learning: for better or for worse. Neuroscientist 5:353-362

Shors TJ, Servatius RJ (1997): The contribution of stressor intensity, duration and context to the stress-induced facilitation of associative learning. Neurobiol Learn Mem 68:92-96

Shors TJ, Weiss C, Thompson RF (1992): Stress-induced facilitation of classical conditioning. Science 257:537-539

Smith MA, Makino S, Kvetnansky R, Post RM (1995): Stress and glucocorticoids affect the expression of brainderived neurotrophic factor and neurotrophin-3 mRNA's in the hippocampus. J Neurosci 15:1766-1777

Stein M, Koverola C, Hanna C, Torchia MG, McClarty B (1997): Hippocampal volume in women victimized by childhood sexual abuse. Psychol Med 27:951-959

Vaidya VA, Marek GJ, Aghajanian GK, Duman RS (1997): 5-HT2A receptor-mediated regulation of brain-derived neurotrophic factor mRNA in the hippocampus and the neocortex. J Neurosci 17:2785-2795
Vaidya VA, Terwilliger RMZ, Duman RS (1999): Role of 5-HT2A receptors in the stress-induced down-regulation of brain-derived neurotrophic factor expression in rat hippocampus Neurosci Lett 262:1-4

Vakili K, Pillay SS, Lafer B, Fava M, Renshaw PF. Bonello-Cintrol CM, Yurgelun-Todd DA (2000): Hippocampal volume in primary unipolar major depression: a magnetic resonance imaging study. Biol Psychiatry 47:087-1090

Wolfe J, Schlesinger LK (1997): Performance of PTSD patients on standard tests of memory. Implications for trauma. Ann NY Acad Sci 821:208-218

Xavier GF, Oliveira-Filho FJB, Santos AGM (1999): Dentate gyrus-selective colchicine lesion and disruption of performance in spatial tasks: difficulties in "place strategy" because of a lack of flexibility in the use of environmental cues? Hippocampus 9:668-681

Yousef G, Ryan WJ, Lambert T, Pitt B, Kellett J (1998): A preliminary report: a new scale to identify the pseudodementia syndrome. Int J Geriatric Psychiatry 13:389-399

Zetterstrom TSC, Pei Q, Madhav TR, Coppell AL, Lewis L, Grahame-Smith DG (1999): Manipulations of brain 5-HT levels affect gene expression for BDNF in rat brain. Neuropharmacology 38:1063-1073 